\title{
DAKWAH REVOLUSIONER MUHAMMAD BIN ABD AL-WAHHAB UNTUK PEMURNIAN AJARAN ISLAM
}

\author{
NAILA FARAH \\ IAIN Syekh Nur Jati Cirebon
}

\begin{abstract}
Abstrak: Pada kurun waktu abad ke $18 \mathrm{M}$ peradaban Islam sedang mengalami stagnasi, kejumudan dan bahkan kemunduran. Umat Islam banyak yang melakukan bidah dan khurafat, suatu perbuatan yang menyimpang dari Aqidah Islam. Muhammad bin Abd al-Wahhab mencoba dengan kreativitas pemikirannya membedah persoalan tersebut melalui ideidenya untuk memurnikan akidah umat Islam yang telah menyimpang dari ajaran tauhid. Tulisan ini memapaparkan apa sebenarnya yang dilakukan oleh Muhhamad bin Abd al-Wahhab dalam melakukan dakwah untuk meluruskan akidah umat yang telah menyimpang tersebut, dan bagaimana sebenarnya pemahaman serta respon para pengikut Muhammad bin Abd al-Wahhab terhadap ajaran/paham yang dianut oleh Muhammad bin Abd al-Wahhab dalam melakukan dakwah tersebut, karena Muhammad bin Abd al-Wahhab sendiri dalam melakukan dakwahnya ternyata tidak pernah seradikal para pengikutnya.
\end{abstract}

Kata-kata Kunci : Muhhamd bin Abd al-Wahhab, Gerakan Wahabiyyah, purifikasi Islam, gerakan fundamentalisme, dakwah revolusioner.

\section{A. Pendahuluan}

Dakwah merupakan salah satu doktrin Islam yang menjadi tugas dan kewajiban bagi setiap individu Muslim. Dalam ajaran Islam, usaha menyebarluaskan kebenaran dan mengajak orang-orang yang belum mempercayainya merupakan tugas suci. Doktrin amar maruf nafi munkar telah menjadi semangat untuk memperjuangkan kebenaran ajaran dan nilainilai Islam yang diyakininya serta mewujudkan masyarakat Muslim yang berjalan diatas rel kebenaran syariat/ajaran Islam tersebut.

Studi tentang gerakan dakwah oleh para pemikir dan pembaharu Muslim akan selalu berkaitan erat dengan proses perkembangan sejarah, dan dimana suatu peradaban harus melewati fase-fase perubahan yang bermacammacam, melalui proses asimilasi dan deversifikasi. Islam adalah abadi, tetapi ajaran-ajarannya akan selalu terkait dengan perjalanan waktu dan 
perkembangan pengetahuan manusia sehingga memberikan efek yang besar bagi kehidupan masyatakat pada masanya (Sardar, 1979:80).

Munculnya pemikir dan pembaharu setiap masa tertentu disebabkan adanya masalah yang timbul ditengah zamannya. Masalah itu terjadi karena ada kesejangan antara ajaran ideal dan realitas masyarakat. Pada kurun waktu abad ke-18 M peradaban Islam sedang mengalami stagnasi, kejumudan dan bahkan kemunduran. Umat Islam banyak yang melakukan bidah dan khurafat yang cenderung mengarah kepada perbuatan animistis, suatu perbuatan yang menyimpang dari ajaran Islam. Persoalan yang sedang melanda dan mewabah umat Islam itu dihadapi oleh Muhammad bin Abd al-Wahhab. Ia mencoba dengan kreativitas pemikirannya membedah persoalan tersebut melalui ideidenya untuk memurnikan akidah umat Islam yang telah menyimpang dari ajaran Tauhid.

Tulisan ini akan membahas sebenarnya yang dilakukan oleh Muhhamad bin Abd al-Wahhab dalam melakukan dakwah untuk meluruskan akidah umat yang telah menyimpang tersebut, dan bagaimana sebenarnya pemahaman serta respon para pengikut Muhammad bin Abd al-Wahhab terhadap ajaran/paham yang dianut oleh Muhammad bin Abd al-Wahhab sendiri dalam melakukan dakwah tersebut, karena Muhammad bin Abd alWahhab sendiri dalam melakukan dakwahnya ternyata tidak pernah seradikal para pengikutnya.

\section{B. Riwayat Hidup Singkat}

Muhammad bin Abd al-Wahhab bin Sulaiman al-Wahhabi al Tamimi, lahir pada tahun 1115 H/1703 M di Uyaynah daerah Nejed, Saudi Arabia. Ayahnya adalah seorang hakim di daerah itu, dan kakeknya, Syekh Sulaiman, adalah seorang ulama Nejed. Muhammad bin Abd al-Wahhab belajar ilmuilmu agama dan menyukai kajian-kajian Al-Quran dan Hadis. Pendidikan dasar pertamanya diperoleh dari ayahnya, kemudian belajar ilmu fiqh dan hadis kepada Syeikh Muwaffak al-Din bin Kudama di masjid Uyaynah. Setalah itu belajar fiqh mahzab Hanafi kepada Muhammad bin Hayat al-Sindi dan mengambil mahzab Hambali kepada Syeikh bin Basyir di Madinah, serta belajar tentang fiqh dan pemikiran Ibnu Taimiyah kepada Syekh Abdullah bin Ibrahim al-Najdi (Gibb dan Kramers, 1965:618; Nasution, 1992:3).

Pada saat itu kitab Bin Taimiya, Al-Fatawa telah menjadi sumber rujukan kebanyakan ulama di daerah ini (Asy-Syaukani, 1297 H:3). 
Sebagaimana para ulama lain pada masanya, Muhammad bin Abdul alWahhab juga merupakan pengikut Ibnu Taimiyah, bahkan ia dianggap sebagai penerus aliran salaf bin Taimiyah tersebut (Nasurion, 1975: 25).

Muhammad bin Abd al-Wahhab melakukan pengembaraan untuk memperdalam ilmu-ilmu Al-Quran dan Sunnah di berbagai kota seperti Madinah, Mekkah, Basrah, dan beberapa kota penting lainnya di Arab Saudi. Selain itu ia juga berkunjung ke beberapa kota diluar Arab Saudi seperti Baghdad, Kurdisyan, dan Isfahan. Di kota-kota yang dikunjunginya, ia mempelajari berbagai ilmu termasuk filsafat dan tasawuf. Setelah bertahuntahun merantau kemudian ia kembali ke desa Uyaynah Nejed. Selama melakukan perjalanan itu, ia melihat adanya praktek-praktek keagamaan yang menurutnya kemudian dianggap menyimpang (Nasution, 1992:975; Gibb dan Kramers, 1965:618).

Kecintaanya kepada Al-Quran dan Sunnah mendorongnya untuk mengjhidupkan dua sumber utama Islam ini dan mengaplikasikannya dalam kehidupan modern kaum muslim.Ia kemudian memperkenalkan jargon "kembali kepada Al-Quran dan Sunnah". Ia berpendapat bahwa inti dari seluruh ajaran Islam adalah Al-Quran dan Sunnah Nabi, karena itu ia meyerukan pemurnian ajaran Islam harus dilandasi dengan dua kitab utama umat Muslim ini.Muhammad bin al-Abd Wahhab tak sekadar mengajak kaum muslim kembali kepada ajaran-ajaran Al-Quran dan Sunnah, tetapi juga menganjurkan mereka melawan dan memusnahkan praktik-praktik yang dianggap bertentangan dengan ajaran-ajaran yang terkandung dalam dua sumber utama Islam itu (Kramers, 1965:619).

Pada tahun $1740 \mathrm{M}$, di kampung halamannya ia mulai mengadakan pengajaran tentang ilmu yang mempelajari dan berusaha mengadakan perubahan terhadap ajaran-ajaran tradisi yang dianggap telah menyimpang dari ajaran Islam. Kegiatannya berlangsung mendapat tantangan dari keluarganya yaitu Sulaiman bin Wahhab (saudaranya) dan Abdullah bin Husein (sepupunya). Gerakan yang dilakukannya menimbulkan pro dan kontra sehingga di Uyaynah timbul perselisihan sampai terjadi pertumpahan darah. Sebenarnya Gubernur (amir) Unaynah mendukung gerakan ini, akan tetapi pemerintah Turki mencurigai gerakan Wahhabi ini, sehingga atas pertimbangan keamanan ia dan keluarganya mengungsi ke Dariyah (Gibb dan Kramers, 1965:618). 
Di Dariyah ini ide-idenya dapat diterima dengan baik oleh Gubernur (amir) Dariyah, Muhammad bin Saud, bahkan mengadakan kerjasama pada tahun $1744 \mathrm{M}$ dan ia bersedia membantu menyebarluaskan gagasannya melalui kekuasaan politik yang dimilikinya (Gibb dan Kramers, 1965:618). Mereka mengadakan kesepakatan untuk bersama-sama melindungi agama, dan melaksanakan Al-Quran dan Sunnah, memerangi Bidah, khurafat, serta menyerukan umat untuk berjihad. Dalam mewujudkan ide-idenya ia bekerja keras dan aktif mendidik masyarakat melalui famplet-famplet, surat, dan menulis kitab. Diantara kitab-kitab yang ditulisnya adalah Kitab at-Tauhid, yang menjadi rujukan utama bagi murid dan pengikutnya, tafsir al-fatihah, tafsir asy-Syahadah wa Marifatullah. At-Taudih an Tawhid al-Akhlaq (Hasyim, 1990: 451).

Karya-karya Muhhamad bin Abd al-Wahhab memiliki nuansa teologis (ilmu tauhid) yang kental. Karena itu banyak orang yang menaggapnya lebih sebagai teolog daripada seorang faqih (ahli fiqh) atau musaffir (ahli tafsir), walaupun ia juga menulis beberapa buku fiqh dan tafsir. Hal ini berkaitan dengan sikap dan semangat Muhhamad bin Abd al-Wahhab untuk memurnikan ajaran-ajaran Islam. Menurutnya, pemurnian Islam bisa terlaksana selama persoalan-persoalan akidah mereka masih tercemari.

Dengan pemerintahan di Dariyah ini, Muhhamad bin Abd al-Wahhab menjabat sebagai penasehat amir, imam dan juga pengawas. Ia membentuk "Mutawwa", kelompok pemuda yang melakukan dakwah untuk menyebarkan agama yang benar sesuai dengan Al-Quran dan Sunnah kepada semua kabilah (Tim Penyusun, 1993:752).

Karena ajaran dan faham purifikasinya mendapat dukungan dari pengausa setempat, yakni amir wilayah Dariyah, maka waktu itu yang relatif singkat ajaran Muhhamad bin Abd al-Wahhab telah tersebar di Jazirah Arab, Muhammad bin Abd al-Wahhab meninggal dunia pada tahun 1206 H/1791 M (Gibb dan Kramers, 1965:619).

\section{Purifikasi Ajaran Islam}

Pada abad ke $18 \mathrm{M}$ peradaban Islam sedang mengalami kemunduran dala berbagai sektor: politik, ekonomi, dan ilmu pengetahuan. Para penguasa banyak yang terjerumus pada hal-hal yang bersifat negatif, seperti sikap korup, dan memeras rakyat. kehidupan masyarakat menjadi tidak aman karena sering terjadi tindak kejahatan dimana-mana. Agama menjadi beku 
karen diselubungi oleh khurafat dan faham sufian yang mistis, masjid-masjid telah ditinggalkan oleh sebagian besar kaum awam, mereka menghias diri dengan azimat sebagai penangkal penyakit, mendatangi kuburan-kuburan yang dianggap keramat, memujanya sebagai perantara (wasilah) kepada Allah, karena muncul anggapan bahwa manusia biasa sangat jauh dengan Allah dan tak daoat mengabdi secara langsung (Stoddard, 1965:34). Hal ini seperti merupakan pengaruh dari ajaran tariqat yang menyatakan bahwa permohonan doa tidak dapat langsung dipanjatkan kepada Allah tetapi harus wasilah para wali atau syeikh yang dipandang mendekati Tuhan, bahkan faham anisme masih menggejala dikalangan umat Islam, pohon dan batu besar diyakini memiliki kekuatan ghaib, disitu mereka memohon pertolongan dan memanjatkan doa (Umairah, 1980:8).

Masyarakat tidak lagi menghiraukan ajaran Al-Quran dan Sunnah, minuman Khamr, perjudian dan pelacuran telah mewabah secara umum, semua berlangsung tanpa ada rasa takut dan malu, kehormatan diri benarbenar telah rusak (Stodard, 1965:34).

Kehidupan masyarakat Islam di Nejed, tempat kelahiran Muhhamad bin Abd al-Wahhab, sudah tidak mencerminkan kehidupan yang Islami lagi. Mereka tidak berakidah tauhid yang murni, banyak yang tenggelam dalam kemusryikan, kezaliman, dan kejahatan dengan meninggalkan ajaran AlQuran dan Sunnah. Mereka tidak akan mentaati ajaran agama yang memerintahkan kebaikan dan melarang keburukan, karena aqidahnya telah rusak dikotori oleh kemusyrikan, dan cara ibadah yang telah menyimpang dari ketauhidan yang murni (Attar, 1967:32).

Demikian juga yang terjadi di kota Mekkah dan Madinah. Kedua tempat itu menjadi tidak "suci" sebagaimana ajaran Islam yang murni, ibadah haji menjadi amalan yang disalahgunakan tidak sesuai dengan yang diajarkan oleh Nabi Muhammad SAW, terjadi pengangung agungan berlebihan terhadap kuburan Nabi dan para sahabatnya. Momen ziarah yang sering digunakan kaum muslimin di kota suci itu, menurut Muhhamad bin Abd alWahhab, telah menjadi ajang praktik kemusyrikan dan kemaksiatan atas nama ibadah. Kondisi umat ketika itu benar-benar dalam kejumudan dan kegelapan (Attar, 1967:35).

Muhhamad bin Abd al-Wahhab dibesarkan dalam situasi sosial seperti itu. Sebagai orang yang dibesarkan di lingkungan penganut paham Hambali, Muhhamad bin Abd al-Wahhab adalah seorang yang puritan dalam 
praktif keagamaan. Sama seperti bin Hambal (pendiri Mahzab Hambali) sendiri dan pengikut-pengikutnya kemudian (seperti Ibnu Taimiyyah dan Ibnu Al-Qayyim Al-Jauziyyah), Muhhamad bin Abd al-Wahhab bersikap tegas kepada lingkungannya yang dianggap menyimpang dari ajaran-ajaran Islam. Dengan modal fiqh mahzab Hambali yang dikenal tegas, untuk tidak mengatakan kaku, dan sikap teologis model Ibnu Taimiyyah yang keras, Muhhamad bin Abd al-Wahhab bertekad memerangi segala bentuk kebidahan dalam beribadah dan kemusyrikan dalam beraqidah.

Dari pengalaman dan ilmu yang diperolehnya, ia merasa prihatin melihat situasi kemusyrikan dan kejumudan berfikir yang demikian itu, sehingga ia pun berusaha untuk merubah kondisi umat Islam yang dianggap sudah menyimpang jauh dari ajaran Al-Quran dan Sunnah Nabi, terutama penyimpangan terhadap aqidah Islam yaitu tauhid. Untuk mengoreksi dan meluruskan aqidah umat itu ia menulis kitab al-Tauhid allazi huwa Haqq Allah Ala al-ibad yang berisi tentang keutamaan tauhid dan perbuatan dosa yang menyebabkan hilangnya tauhid bagi seorang muslim serta berbagai macam perbuatan yang menyebabkan syirik kepada Allah. Pokok-pokok isi Kitab al-Tawhid diantaranya adalah :

1. Yang boleh dan harus disembah hanyalah Allah SWT semata, orang yang menyembah selain Allah SWT telah menjadi musyrik dan boleh dibunuh.

2. Kebanyakan dari umat Islam bukan lagi penganut paham tauhid yang sebenarnya, karena mereka meminta pertolongan bukan lagi kepada Allah, tetapi dari Syeikh atau wali dari kekuatan gaib. Orang Islam yang demikian juga menjadi musyrik.

3. Menyebut Nabi, Malaikat atau Syeikh sebagai perantara doa (wasilah) juga merupakan perbuatan syirik.

4. Meminta syafaat selain dari Allah merupakan perbuatan syirik.

5. Nazar bukan karena Allah juga merupakan perbuatan syirik.

6. Bersumpah dengan nama selain Allah adalah perbuatan syirik.

7. Tidak percaya kepada qada dan qadar Allah merupakan kekufuran.

8. Memperoleh pengetahuan selain dari AL-Quran, Hadis dan qiyas merupakan kekufuran. 
9. Demikian pula penafsiran Al-Quran dengan tawil (interprestasi bebas) adalah kufur. (Gibb dan Kramers, 1965:619: Nasution, 1975:25).

Bila dilihat dari segi isinya Kitab at-Tawhid juga berfungsi sebagai penghujat terhadap kepercayaan yang telah menyimpang dari ajaran tauhid, juga merupakan pedoman bagi pengikutnya untuk meluruskan aqidah umat. Sehingga parapengikutnya menamakan diri al-Muwahhidun karena berusaha memurnikan ajaran tauhid, sebutan Wahhabi dimunculkan bukan dari pengikutnya (Gibb dan Kramers, 1965:618). Istilah Muwahhidun juga digunakan oleh dinasti Barbar di Afrika Utara, pendirinya adalah Binu Tumart (1078-1130 M) dimana dinasti ini mencoba menyatukan wilayahnya dengan asas tauhid sebagai idiom alat pemersatu (Hitti, 1968:546).

Ahmad Amin menjelaskan bahwa Muhhamad bin Abd al-Wahhab untuk memajukan umat Islam adalah dengan jalan memurnikan tauhid dari faham-faham "asing” dari luar Islam. Muhhamad bin Abd al-Wahhab merasa khawatir dan sangat prihatin jika umat Islam sampai jatuh ke dalam "lembah" kemusyrikan serta mengakibatkan kelemahan dan kerukunan dan keruntuhan Agama Islam (Amin, 1965:10).

Tauhid merupakan ajaran fundamental dalam islam, karena itu Muhammad bin Abd al-Wahhab memusatkan perhatian dalam gerakannya kepada usaha untuk memurnikan kepercayaan masyarakat dari segala bentuk khurafat dan bidah. Ia menolak praktek-praktek ajaran yanng tidak ada landasannya dari Al-Quran dan Sunnah. Fenomena masyarakat telah menunjukkan adanya bidah yang merendahkan derajat agama (Rahman, 1984;289), maka dengan waktu yang telah dirasakan mendesak umat islam harus segera kembali kepada Islam asli/murni,yaitu islam sebagaimana yang dianut dan di praktekkan pada zaman Nabi Muhammad SAW dan para sahabatnya (Gibb, 1993;136). Sebenarnya, apa yang dilakukan oleh Muhammad bin Abd al-Wahhab tentang seruan kepada umat islam agar kembali kepada ajaran yang asli sama seprti yang telah dilakukan oleh Ibnu Taimiyah,pendahulunya pada abad ke-13 dan ke-14 M, dalam rangka pemurnian ajaran Islam (Gibb,1993;136).

Menurut Muhammad bin Abd al-Wahhab, sebagaimana juga di katakan Ibnu Taimiyah, di dalam aqidah tauhid yang murni ada tiga aspek pokok, yaitu; Pertama, Tauhid Rububiyyah, yakni pengakuan hanya Allah SWT semata yang merupakan tuhan pencipta pemelihara, pengatur serta 
perencana hidup dan mati seluruh makhluk. Kedua, Tauhid al-Asma wa alsifat, yakni beriman dengan yakin terhadap apa yang telah di tetapkan Allah dan Rasul-nya tentang nama dan Sifat Tuhan sebagaimana yang terdapat dan tercantum dalam Al-quran dan sunnah tanpa dilakukannya tamsil, tawil, tasybih maupun tatil, Tuhanlah yang lebih mengetahui (tafwid) tentang masalah ini. Ketiga, Tauhid Ibadah, yakni menegaskan Allah di dalam segala bentuk peribadatan dan ketaatan tanpa membuat perantara (tawassul). Tauhid ibadah ini disebut juga dengan Tauhid Uluhiyyah (Ibnu Muhammad, 1971:33).

Ajaran lain yang dianut dan disebarkan oleh Muhhamad bin Abd alWahhab adalah kesederhanaan dalam hidup. Semua barang mewah dilarang, di masjid-masjid didirkan harus sederhana, perhiasan-perhiasan dikubur atau masjid, demikian pula kiswah kabah harus diturunkan. Berpakaian sutera, makanan yang mewah, minum anggur, merokok, dan segala macam perbuatan boros lainnya dilarang, karena tidak bermanfaat, bahkan memakai tasbih untuk menghitung zikir (wirid) juga dilarang. Salat berjamaah setiap waktu wajib dilaksanakan di masjid dengan pengawasan ketat. Hukuman Qiyas, rajam, dan potong tangan dilaksanakan kembali dengan resmi dihadapan umum (Muhammad, 1971:33).

Ide pemurnian yang dimunculkan oleh Muhhamad bin Abd alWahhab, sebagaimana telah disebutkan, banyak dipengaruhi oleh pemikiran bin Taimiyyah. Meskipun pada masa mudanya Muhhamad bin Abd alWahhab adalah penganut sufi, namun akhirnya terpengaruh oleh tulisantulisan Ibnu Taimiyyah dan doktrin intelektual sufi yang mempengaruhi kepercayaan masyarakat (Rahman, 1984:288). Sikapnya tegas terhadap prkatik-praktik keagamaan yang menyimpang, khususnya praktik-praktik yang berbau musyrik, membuat Muhhamad bin Abd al-Wahhab tidak mentoleransi kaum sufi yang menurutnya sebagai sumber meluasnya praktikpraktik kemusyrikan. Sikap antagonistik terhadap sufi dan tasawuf sebetulnya tak hanya bersumber dari pengalaman pribadi Muhhamad bin Abd alWahhab sendiri, khususnya ketika ia berkunjung ke beberapa kota di Irak dan Iran dimana ia menjumpai banyak penganut sufi yang melakukan praktik ibadat pemujaan di kuburan tokoh-tokoh agama. Tapi, sikap semacam itu adalah warisan asli Ibnu Taimiyyah dan Ibnu Qayyim Al-Jauziyyah, dan dua Hambali yang sangat mempengaruhi cara dan sikap berfikir Muhhamad bin Abd al-Wahhab (Rahman, 1984:288). 
Muhhamad bin Abd al-Wahhab tak hanya menolak praktik-praktik yang dilakukan sebagian besar kaum sufi, khususnya menyangkut keyakinan terhadap wasilah (perantara), tetapi juga menolak struktur ajaran sufi dan mengganggapnya sebagai bagian bidah dan syirik. Penolakan ini konsekuensi logis dari sikap teologis Muhhamad bin Abd al-Wahhab yang tegas terhadap taqhid (pengesaan Allah), bahwa keyakinan terhadap keesaan Allah tidak seharusnya dikotori dengan praktik-praktik yang membawa kemusyrikan, kendati praktik-praktik itu berbau keagamaan. Satu-satunya hal yang diakui baik dari ajaran sufi adalah menyuian diri. Tetapi menurut, Muhhamad bin Abd al-Wahhab, orang tak perlu menjadi sufi kalau hanya melakukan pembersihan diri (Assyaukannie, 2004).

Salahsatu praktik yang dibenci Muhhamad bin Abd al-Wahhab adalah praktik wasilah dan kepatuhan berlebihan terhadap tokoh-tokoh agama yang dianggap suci. Praktik ini, menurut Muhhamad bin Abd al-Wahhab, selain tidak memiliki dasar perintah yang jelas, baik dari Al-Quran maupun Sunnah, praktik semacam itu juga merugikan umat Islam. Salahsatu dampaknya adalah luasnya sikap taqlid (pengikutan secara membabi buta) di kalangan umat Islam. Sikap taqlid, menurut Muhhamad bin Abd al-Wahhab adalah salah satu penyebab kemunduran kaum muslim modern. Kendati tidak menganjurkan perlunya setiap orang menjadi mujtahid (pembaharu fiqh), ia menganjurkan kaum muslim agar independen dan tidak bergantung kepada pendapat orang lain (Assyaukanie, 2004).

Dalam bidang pemikrian hukum, ia sangat menentang orang-orang yang berbuat taqlid yang menyebabkan kejumudan kreativitas berfikir dan hanya bergantung kepada kitab-kitab klasik dan bahkan menganggap seolaholah kitab-kitab itu sebagai sumber kebenaran yang sama kedudukan dengan Al-Quran atau Hadis. Sikap penerimaan yang berlebihan terhadap kitab-kitab itu, menurut Muhhamad bin Abd al-Wahhab hanya menjauhkan umat Islam dari sumber yang seharusnya mereka jadikan acuan utama mereka yakni AlQuran dan Sunnah. Karena itu, sebagaimana halnya Ibnu Taimiyyah, ia juga menyatakan bahwa pintu ijtihad tidaklah tertutup. Salah satu kekuatan untuk memperbaiki kondisi pemikiran umat yang sedang mengalami kemunduran adalah mengaktualkan dan menggalakan cara berfikir positif, serta mengoreksi dengan kritis terhadap pemikiran intelektual sebelumnya agar seseorang tidak terjerumus kepada perbuatan taqlid (Lewis, Holt \& Lambton, 1970:368). Ia menginginkan adanya pemikiran yang bebas tidak terikat oleh 
faham tertentu, karena pemikiran merupakan kekuatan bebas yang besar dari taqlid, juga sebagai penegasan akan hak untuk melakukan ijtihad (Rahman, 1984:288).

Pandangan mengenai kebolehan seorang pemikir dapat melakukan ijtihad hukum antara lain:

1. Bahwa adanya Al-Quran dan Sunnah sejalah yang merupakan sumber asli dari ajaran-ajaran Islam, pendapat para ulama bukanlah sumber ajaran.

2. Taqlid kepada ulama tidak dibenarkan.

3. Pintu ijtihad tidaklah tertutup, akan tetapi terbuka untuk semuanya (Gibb dan Kramers, 1975:26).

Sikap Muhhamad bin Abd al-Wahhab yang mendukung ijtihad dan menolak taqlid menempatkannya sebagai pembaharu Islam sejati. Kendati banyak dipengaruhi oleh Ibnu Taimiyyah dan Ibnu Qayyim al Jauziyyah, ia sendiri mengaku tidak kaku dalam mengikuti pendapat dua ulama besar itu. "Ibnu Taimiyyah dan Ibnu Qayyim al Jauziyyah adalah dua ulama terpandang bagi kaum sunni, tetapi saya tidak mengikuti mereka secara ketat" akunya dalam buku al-Hadyat al-Saniyyah (diedit oleh Sulaiman bin Sahman), sayangnya sikap Muhhamad bin Abd al-Wahhab yang independen dan percaya diri ini tidak diikuti oleh para pengikutnya. Para pengikutnya Muhhamad Bin Abd al-Wahhab yang dikenal sebagai Wahhabi cenderung tertutup serta sangat fanatik terhadap pandangan-pandangan gurunya. Dalam beberapa hal, mereka bahkan melakukan praktik taqlid, suatu yang dibenci oleh Muhhamad bin Abd al-Wahhab sendiri (Assyaukanie, 2004).

Ajaran-ajaran Muhhamad bin Abd al-Wahhab menyebar secara luas sejak Muhammad bin Saud, seorang pemimpin suku dari Dariyyah, sebuah kawasan di Hijaz Arab, berhasil membangun kekuatan sebagai cikal bakal negara Arab Saudi pada awal tahun 1800-an. Setelah Ibnu Saud menaklukan Mekkah pada tahun 1803, ajaran-ajaran Muhhamad bin Abd al-Wahhab diadopsi sebagai doktrin resmi kerajaan hingga sekarang.

\section{Gerakan Wahhabi dan Pengaruhnya}

Sepeninggal Muhhamad bin Abd al-Wahhab pada tahun $1206 \mathrm{H} / 1791$ $\mathrm{M}$, ajarannya berkembang pesat berkat para pengikutnya dengan didukung oleh penguasa setempat dan menjadi sebuah gerakan yang disebut sebagai gerakan Wahhabi (para pengikutnya sendiri menamakan dirinya Gerakan Al- 
Muwahhidun karena ajarannya berusaha memurnikan paham tauhid, namun pada kurun waktu selanjutnya gerakan dikenal dengan gerakan Wahhabi, sesuai dengan nama pendirinya). Gerakan Wahabbi memegang teguh aliran puritan, yakni usaha untuk mengembalikan dan memurnikan keyakinan serta pengalaman Islam sebagaimana ulama salaf, dengan membersihkan dan menghapus berbagai macam bidah dan khurafat agar umat Islam kembali kepada dua sumber asas yaitu Al-Quran dan Sunnah (Gibb, 1993:136).

Gerakan Wahhabi ini pada perkembangan selanjutnya, karena adanya dukungan dari penguasa, menjelma menjadi gerakan militer yang menaklukan daerah-daerah sekitarnya. Kota Riyad menjadi daerah pertama yang ditaklukan pada tahun 1773 M, kemudian Karbela dapat diduduki dan dibersihkan dari segala sumber bidah dan khurafat. Kedua kota tersebut merupakan tempat ziarah orang-orang Syiah dimana menjadi penghormatan yang berlebihan terhadap makam Ali bin Abi Thalib dan anaknya mati syahid di Padang Karbala. Kota suci Mekkah dapat dikuasi pada tahun 1803 M serta dibersihkan dari segala hal yang berbau penyembahan terhadap manusia. Kubah-kubah kuburan para Sahabat diradakan dengan tanah. Kemudian kota Madinah dapat diduduki pada tahun $1806 \mathrm{M}$, tindakan pembersihan sebagaimana yang dilakukan di Mekkah dan tempat-tempat lain dilakukan pula di kota ini, namun kuburan Nabi tidak jadi dirusak dengan pertimbangan kemungkinan ada reaksi kaum muslimin sedunia yang hebat apabila yang satu ini dilaksanakan (Tim Penyusun, 1993:753).

Kemajuan yang diperoleh gerakan Wahhabi mencemaskan kerajaan Turki Ustamani di Istanbul sebagai pusat pemerintahan Islam pada waktu itu, maka Sultan Mahmud II pun mengirim ekspedisi dibawah pimpinan Muhammad Ali untuk mematahkan gerakan tersebut. Pada tahun 1812 Makkah dan Madinah dapat dikuasi, namun gerakan Wahhabi tidaklah surut sampai disitu. Pada abad ke 19 gerakan Wahhabi di Jazirah Arab muncul kembali dengan dipimpin oleh Abdullah bin Saud, anak al-Aziz bin Saud, serta dapat menguasai kembali kedua kota suci Mekkah dan Madinah, akan tetapi Ibrahim Pasha anak Muhammad Ali, dapat menggempur dan mengalahkannya. Benteng pertahanan Wahhabi di Dariyyah diratakan dan Abdullah bin Saud dapat ditangkap kemudian dibawa ke Turki untuk dihukum pancung di lapangan Masjid Aya Shopia pada tahun 1818. Akan tetapi keturunan Ibnu Saud berhasil mengkonsulidasikan kekuatan Wahhabiyah kembali, dan di bawah kepemimpinan Abd al-Aziz bin Abd al- 
Rahman pada tahun 1925 dapat berkuasa kembali serta membangun kerajaan Wahhabiyah yang kemudian menjelma menjadi Kerajaan Arab Saudi hingga saat ini (Tim Penyusu, 1993:753).

Kemunculan gerakan Wahhabi dipandang sebagai kembangkitan kembali Islam ortodoks. Sebab-sebab kemunculannya ditandai dengan adanya "krisis" yang dihadapi umat Islam baik secara spritual maupun politis. Penyebaran gerakan dibawah ini ke berbagai negara disebabkan karena kaum Wahhabi menguasai kedua kota suci Makkah dan Madinah, sehingga ajarannya dapat dipelajari oleh orang-orang yang menunaikan ibadah haji dan orang-orang pendatang yang bermukim di kedua kota tersebut. Gerakan Wahhabi sedikitnya telah memberikan inspirasi bagi pelaku-pelaku reformasi dan menyebarkan benih kebangkitan Islam/Pan-Islamisme (Stoddard, 1965:45). Para pelaku reformasi sesudah Muhhamad bin Abd al-Wahhab seperti Ahmad Khan (1817-159) dengan gerakan Aligarh di India dan Muhammad Sanusi (1787-1859) di Afrika Utara dengan gerakan sufi dan rekatnya yang militeristik, keduanya merupakan tokoh yang mengambil corak yang sama dengan gerakan Wahhabi.

Sedangkan para pembaru lain seperti Muhammad Abduh (18491905), Rasyid Rida (1865-1935) dan Amir Syakib Arsalan (1869-1946), mereka memiliki kemiripan pandangan dalam pengambilan hujjah, bahwa untuk membersihkan keyakinan umat Islam dari pengaruh taqlid khurafat dan bidah umat Islam harus dikembalikan kepada pengamalan ajaran yang asli yaitu bersumber dari Al-Quran dan Sunnah Rasul (Donohue dan Esposito, 1990:101).

Adapun pengaruh ajaran Wahhabi pada pemikiran dan gerakan Islam di Indonesia memunculkan gerakan Paderi (mulai 1803) hingga menimbulkan perang dari tahun 1821-1837. Pada abad ke 20 paham Wahhabi di Indonesia dipelopori oleh Haji Abdul Malik Karim Amrullah (Hamka), Djamil Djambek, KH. Ahmad Dahlan (Stoddard, 1965:46).

\section{E. Penutup}

Muhhamad bin Abd al-Wahhab merupakan seorang pelaku reformasi ajaran Islam dan dakwahnya lebih cenderung untuk pemurnian dari berbagai pembaruan, sebab ajarannya lebih menitik beratkan kepada pemurnian akidah umat Islam dari sikap dan prilaku Syirik, khurafat dan bidah yang dikembalikan kepada ajaran asli yaitu ajaran yang bersumber dari Al-Quran 
dan Sunnag Nabi SAW. Namun demikian, sikap yang mendukung ijtihad dan menolak taqlid menempatkannya sebagao pembaharu Islam sejati, walaupun banyak dipengaruhi oleh pemikiran dan karya-karya Ibnu Taimiyyah dan Ibnu Qayyim al Jauziyyah ia sendiri mengaku tidak kaku dalam mengikuti dua ulama besar.

Dakwah yang dilakukan oleh Muhhamad bin Abd al-Wahhab dalam meluruskan akidah umat dari pengaruh syirik, khurafat, dan bidah ternyata tidak seradikal apa yang dilakukan pengikutnya setelah dia meninggal. Bahwa Muhhamad bin Abd al-Wahhab tidak pernah menyuruh muridmuridnya untuk membongkar nisan-nisan kuburan para sahabat Nabi dan simbol-simbol keagamaan lainnya di tempat tempat suci seperti Mekkah dan Madinah. Tetapi para pengikutnya, khususnya setelah Kerajaan Arab Saudi berdiri dan mengadopsi ajaran Muhhamad bin Abd al-Wahhab, mengambil langkah yang sangat radikal dalam membersihkan praktek-praktek keagamaan masyarakat di semenanjung Arabia saat itu. Mereka bukan hanya membersihkan keyakinan dan cara berfikir kebanyakan kaum muslim diwilayah itu, tetapi juga membersihkan tempat-tempat dan simbol-simbol keagamaan yang selama itu diagungkan, termasuk nisan-nisan kuburan para Sahabat Nabi dan orang-orang suci di Madinah.

Apa yang telah dilakukan oleh Muhhamad bin Abd al-Wahhab dalam melakukan pemurnian ajaran Islam dan sikap mendukung itjihad serta menolak taqlid, pada akhirnya memperngaruhi hampir gerakanm-gerakan pembaharuan Islam di seluruh dunia, termasuk di Indonesia.

\section{DAFTAR PUSTAKA}

Amin, Ahmad, 1965. Zuama al-Islah fi al-Asr al-Hadis, Kairo : Maktabah alNahdah al-Misriyyah

Assyaukanie, Luthfi, 2004, "Muhammad Bin Abd al-Wahhab (1703-1791)" artikel dalam situs www.islamlib.com, dimuat tanggal 12 Januari 2004.

Attar, Ahmad Abd al-Jafar, 1967.Muhammad bin Abd al-Wahab, Beirut:tnp.

Donohue, Jogn J. \& John L. Eposito, 1990. Islam dan Pembaharuan, Terj.Jakarta: Rajawali Pers.

Gibb, H.A.R. \& J.H Kramers, 196. Shorter Encylopedia of Islam, London: Luzac \& Co. 
Gibb, H.A.R. 1993. Modern Trens in Islam, terj. Machnun Husein, Aliranaliran Modern dalam Islam, Jakarta: Rajawali Pers.

Nasution, Harun (Ed.), 1992, Ensiklopedia Islam Indonesia, Jakarta : Jambatan

Nasution, Harun, 1975, Pembaharuan dalam Islam Sejarah Pemikiran dan Gerakan, Jakarta: Bulan Bintang.

Hasymy, A. 1990. Sejarah Kebudayaan Islam, Jakarta: Bulan Bintang.

Hitti, Philip K, 1968. History of the Arabs, London: MacMillan Publishing. Lewis, Bernard, P.M. Holt \& Ann K.S. Lambton. 1970. The Cambrigde History of Islam, London: Cambridge Univercity Pers.

Muhammad, Sulaiman bin Abdullah Bin, 1971. Taysir al-Aziz al-Hamid fi Syarh kitab al-Tawhid, Beuryt, Maktabah Islamy.

Rahman, Fazlur, 1984. Islam Terj. Ahsin Muahmmad, Bandung: Pustaka.

Sarda, Ziauddin, 1979. The Future of Islamic Civilization, London: British Libary Oublication.

Stoddard, Lothrop. 1965. The New Workd of Islam, terj. Dunia Baru Islam, Jakarta : Perpustakaan Islam.

Syaukani, Imam Muhammad al-, 1297 H. Nay; al-Awtar, Kairo: Dar al Hadis.

Tim Penyusun, 1993. Ensiklopedia Islam di Indonesia, Jakarta: Departemen Agama RI.

Umairah, Abd al-Rahman, 1980. Al-Syubuhat allati Ursirat Hawla Dawah Muhammad bin Abd Wahabb, Riyadh: Jamiiyah al-Imam Muhammad Bin Saud Islamiyyah.

Wahhab, Muhammad bin Abd al- 1968. Kitab Taqhid, Beirut: Dar alArabuyyah li at-Tabaah wa al-Nasyr wa al Tawzi. 